\title{
A Fishnet Metasurface as an Ultra-Thin Quarter Wave Plate
}

\author{
A.O. Perov* \\ O.Ya. Usikov Institute for Radiophysics and Electronics NASU, 12, Akad. Proskura St., 61085 Kharkiv, Ukraine
}

(Received 16 September 2020; revised manuscript received 20 October 2021; published online 25 October 2021)

\begin{abstract}
In the paper, a design of an ultra-thin quarter wave plate using a fishnet metasurface is described. The metasurface is arranged as a periodic array of compound supercells with subwavelength circular holes. Even though the holes are polarization insensitive, it is shown that one can control polarization response manipulating with metasurface supercell asymmetry. A specific phase difference between the $x$ and $y$ components of the transmitted field can be obtained by manipulating with hole locations in the supercell as well as with periodic supercell dimensions. In the design, magnitude and phase of two orthogonal components for the transmitted field can be controlled independently, hence enabling efficient and robust polarization conversion. It is explained that the effect of conversion of a linearly polarized wave into a circularly polarized one is due to enhanced transmission phenomenon through subwavelength holes and coupling with orthogonal eigenmodes of the metasurface. In the case of subwavelength holes, a whole periodic supercell behaves as a scatterer, which combines impacts of the individual elements leading to the strong polarization sensitivity, which cannot be observed in the case of resonant ones. It is analytically shown that the effect of polarization conversion for ultra-thin metasurfaces appears when two orthogonal eigenmodes with closely spaced eigenfrequencies are coupled to the incident field. Analytical formulas to describe the polarization effects as a function of eigenfrequencies are obtained, and the conditions to get the maximum level of the conversion efficiency possible for ultra-thin single layer structures are discussed.
\end{abstract}

Keywords: Polarization conversion, Quarter-wave plate, Subwavelength holes, Metasurface.

DOI: 10.21272/jnep.13(5).05005

PACS numbers: 41.20. - q, 42.25.Bs, 42.25.Ja

\section{INTRODUCTION}

Polarization state is an intrinsic property of electromagnetic waves, and the conversion between polarization states is very often highly desirable for many modern microwave and optical applications [1]. Even though the electromagnetic wave intensity may be constant, valuable information can be conveyed in the polarization state.

To manipulate polarization, various approaches can be applied, which include both conventional structures [1] and recently discovered metamaterials [2,3]. During recent years, conversion among polarization states using metamaterials has attracted increasing interest due to their design flexibility and compactness. Different artificial structures having $3 \mathrm{D}$ or $2 \mathrm{D}$ chirality [4-9], asymmetric fishnet metamaterials [10-18] have been investigated for the goal. It has been reported structures, which are formed with periodically arranged scatterers of different geometric shapes. Some of them have complicated geometry, for example, mutually turned crosses, fractals, gammadions, split-ring resonators. Others have more simple geometry, for example, elliptic or rectangular shapes. It should be noted that for all these designs, polarization state conversion is due to coupling of the incident wave with polarization sensitive scatterers. Manipulating with their shape, one can control polarization response.

However, it has been recently shown $[14,15]$ that periodic structures with very simple polarization insensitive scatterers such as subwavelength circular holes can be applied to control polarization response. The origin of the effect is enhanced transmission phenomenon [19-20], which can lead to enhanced polarization conversion $[14,15]$. For the goal one need to real- ize a regime of coupling of the incident wave with different type symmetry eigenmodes [21, 22], leading to polarization sensitive enhanced transmission.

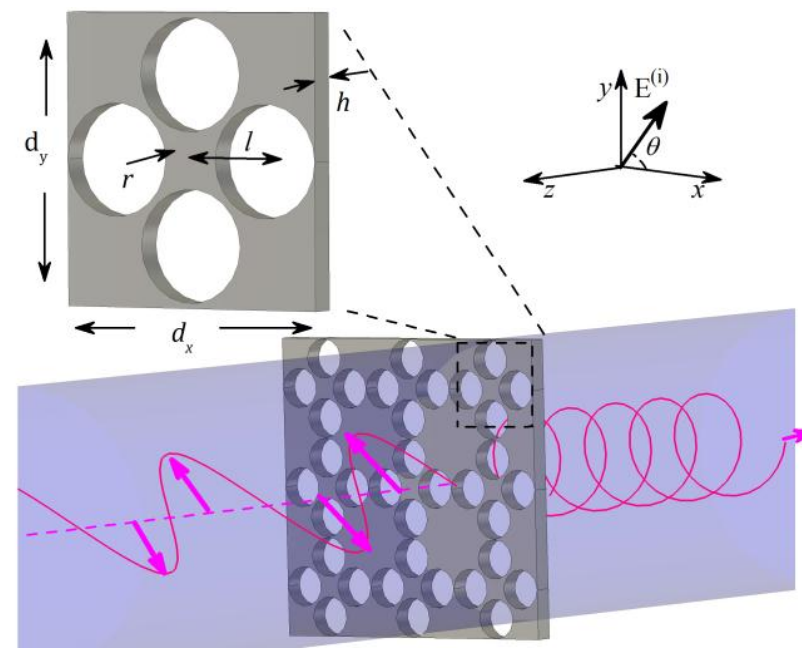

Fig. 1 - A metasurface arranged as a periodic array of compound supercells with subwavelength circular holes in PEC metal. The metasurface is illuminated with a normally incident plane wave polarized at an angle $\theta=45^{\circ}$ to the $x$-axis, converting it into a circularly polarized transmitted wave. The upper-left inset shows a supercell with four circular holes and the corresponding geometrical parameters

Here we consider, computationally, a design of the device consisting of an array of subwavelength circular holes arranged in compound periodic supercells to be applied as an ultra-thin quarter wave plate. The specific phase difference between the $x$ and $y$ components of the transmitted field for the case, in contrast to the one

\footnotetext{
*andrii.perov@gmail.com
} 
considered in [15], can be introduced manipulating with asymmetry of the whole periodic supercell or with appropriate hole locations in it. By introducing more degrees of freedom into the supercell geometry, one can obtain the desired polarization response with less asymmetry in periodic supercell dimensions. Therefore, it allows to get a more compact device due to the more complex filling of the periodic supercell.

\section{THE PROBLEM STATEMENT AND NUMERICAL SIMULATION RESULTS}

Consider a metasurface arranged as a periodic array of compound supercells with subwavelength circular holes in perfect electrically conducting (PEC) metal (Fig. 1) of thickness $h$ with the center plane at $z=0$. The metasurface periodic supercell has dimensions $d x$ and $d_{y}$ along the $x$-axis and $y$-axis directions, respectively (Fig. 1). It contains four identical holes of radius $r$ which are shifted from the supercell center at distance $l$ along the $x$ - or $y$-axis.

The metasurface is excited by a normally incident plane wave with an electric field

$$
\vec{E}^{i n c}=\cos \theta e^{i(2 \pi / \lambda) z-i \omega t} \vec{x}+\sin \theta e^{i(2 \pi / \lambda) z-i \omega t} \vec{y},
$$

where $\theta$ is the polarization angle in the $x O y$ plane and $\lambda$ is the free space wavelength.

The electric field of the transmitted plane wave can be written as

$$
\vec{E}^{\text {trans }}=T_{x}(\kappa) e^{i(2 \pi / \lambda) z-i \omega t} \vec{x}+T_{y}(\kappa) e^{i(2 \pi / \lambda) z-i \omega t} \vec{y},
$$

where $T_{x}(\kappa)$ and $T_{y}(\kappa)$ are the complex magnitudes of $x$ - and $y$-polarized plane waves, respectively; $\kappa=d_{x} / \lambda$ is the relative frequency. To solve the problem, the mode matching method was applied.

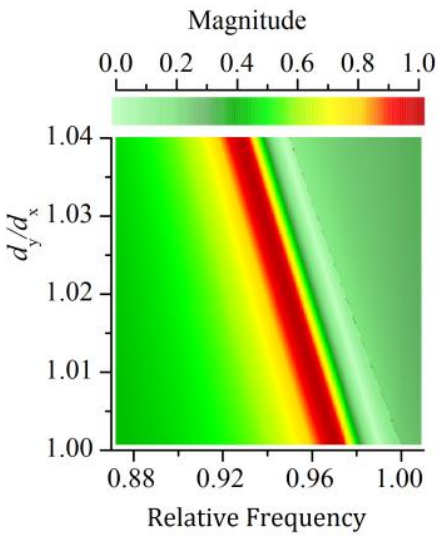

a
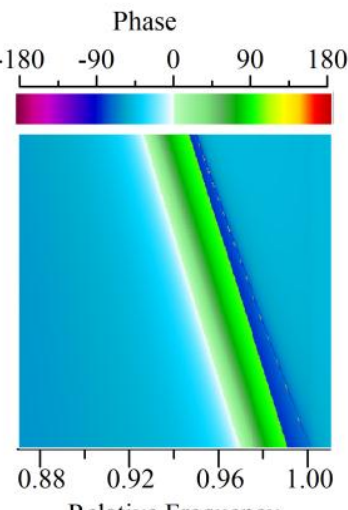

Relative Frequency

b
Fig. 2 - Transmission through the metasurface of thickness $h=0.05 d_{x}$ patterned with circular holes of radius $r=0.19 d_{x}$ for a normally incident plane wave polarized in the $y$-direction: magnitude (a) and phase (b) of the transmitted wave

We start with Fig. 2, where it is shown a plot of the magnitude (Fig. 2a) and phase (Fig. 2b) for a plane wave transmitted through the metasurface of thickness $h=0.05 d_{x}$ with supercell patterned with four circular holes of radius $r=0.19 d x$ which are shifted from the cell center at $l=0.295 d_{x}$. The periodicity $d_{x}$ is constant and the periodicity $d_{y}$ varies from $d_{y}=d_{x}$ to $d_{y}=1.04 d_{x}$. The incident field is polarized in the $y$-axis direction. One can see that the magnitude (Fig. 2a) and phase (Fig. 2b) of the transmitted wave strongly depend on $d_{y}$. When $d_{y}$ increases, the magnitude maximum value accompanied by a characteristic phase shift moves to the lower boundary of the frequency band.

We exploit this observation to manipulate with the polarization state of the transmitted wave. We use different values of periodicities $d_{x}$ and $d_{y}$ to realize different polarization responses for waves incident on the metasurface. If we are able independently manipulate with transmission responses of the waves along the $x$ and $y$ axes, then it will be possible to obtain different phase delay between them, and as consequence to control the polarization state of the transmitted wave for an arbitrary incident wave orientation $\theta$. Fig. 3 illustrates such a possibility.

Fig. 3 shows the transmission magnitudes of two orthogonal linearly polarized waves normally incident on the metasurface. It can be observed that the incident wave polarized along the $x$-axis (Fig. 3a) is insensitive to $d_{y}$ changes. For the orthogonal polarization (Fig. 3b), however, the transmission maximum shifts to lower frequencies as $d_{y}$ increases.

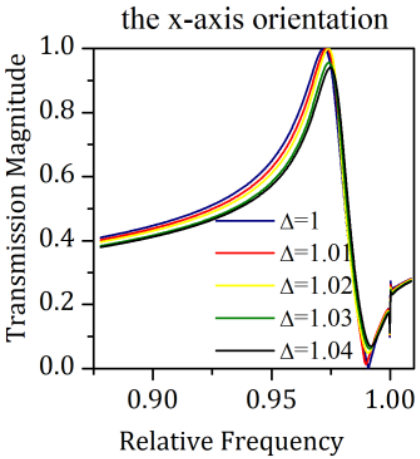

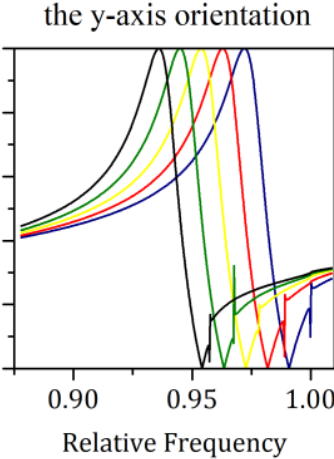

Fig. 3-Transmission magnitude of plane waves polarized along the $x$ and $y$ axes through the metasurface of thickness $h=0.05 d_{x}$ patterned with circular holes $\left(r=0.19 d_{x}\right)$ for different values of periodicity $d_{y}$ : transmission magnitude of the $x$-polarized (a) and $y$-polarized (b) waves

It follows from Fig. 2 and Fig. 3 that two orthogonal components along the $x$-axis and $y$-axis for an incident wave polarized at an arbitrary angle $\theta$ resonate largely independently. Therefore, one can choose geometry parameters to manipulate with magnitudes and phases of the transmitted waves in the $x$ and $y$ directions for the metasurface to behave like a quarter wave plate.

Fig. 4 shows a plot of the magnitude (Fig. 4a) and the ellipticity angle $\chi$ (Fig. 4b) for a plane wave transmitted through the metasurface with geometry parameters $h=0.05 d_{x}$ and $r=0.19 d_{x}$. It is shown the dependence of the transmission response from periodicity $d_{y}$, which varies from $d_{y}=d_{x}$ to $d_{y}=1.04 d_{x}$. The incident wave is polarized at $\theta=45^{\circ}$ to the $x$-axis. 


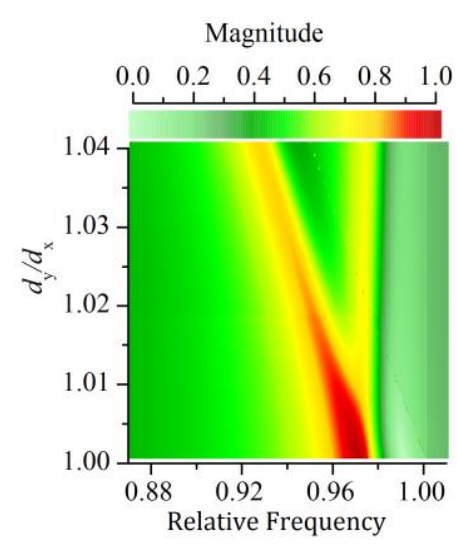

a
Ellipticity Angle $\chi$

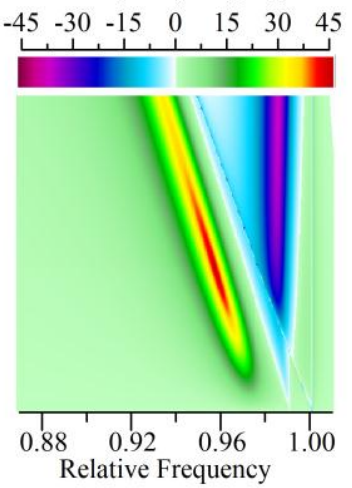

$\mathrm{b}$

Fig. 4 - Transmission of plane waves polarized at $\theta=45^{\circ}$ to the $x$-axis through the metasurface of thickness $h=0.05 d_{x}$ patterned with circular holes of radius $r=0.19 d_{x}$ when periodicity $d_{x}$ is fixed and $d_{y}$ varies: magnitude of the transmitted wave (a), elipticity angle $\chi(b)$

The ellipticity angle is defined as

$$
\chi=\frac{1}{2} \arcsin (\sin (2 \alpha) \sin (\delta)),
$$

where $\alpha=\arctan \left(T_{y} / T_{x} \mid\right)$ and $\delta=\arg \left(T_{y} / T_{x}\right)$ are auxiliary angles representing the ratio of magnitudes and phases for two orthogonal components of the wave transmitted along the $x$-axis and $y$-axis, respectively. The ellipticity angle varies in the range $-45^{\circ} \leq \chi \leq 45^{\circ}$ and takes values $\chi= \pm 45^{\circ}$ for the case of transmitted wave to be right or left circularly polarized one.

Various levels of magnitude as well as polarization states for the transmitted wave are possible to obtain depending on the metasurface geometry parameters. As one can see from Fig. 4, the ellipticity angle $\chi$ continuously changes from $0^{\circ}$ to $45^{\circ}$, and therefore, there are values of the periodicity $d_{\mathrm{y}}$ for the metasurface to behave like a quarter wave plate. The case is illustrated with Fig. 5.

Fig. 5 shows polarization characteristics of the wave transmitted through the metasurface for the case of an incident wave polarized at $\theta=45^{\circ}$ to the $x$-axis, when the screen periodicity $d_{y}$ is equal to $d_{y}=1.023 d_{x}$. One can see that near the frequency $\kappa_{C P}=0.95963$ the axillary angles $\alpha$ (Fig. 5d) and $\delta$ (Fig. 5c), describing relations of magnitudes and phases of the orthogonal components along the $x$-axis and $y$-axis, are equal to $\alpha=45^{\circ}$ and $\delta=90^{\circ}$, respectively. This corresponds to the value of the ellipticity angle $\chi$ which is equal to $45^{\circ}$ (Fig. $5 \mathrm{~b}$ ). This means that the incident wave is converted into a right-handed circularly polarized one. The conversion efficiency near the frequency $\kappa C P$, as one can see from Fig. 5a, takes the maximum possible value for thin single-layer structures, which is $50 \%$.

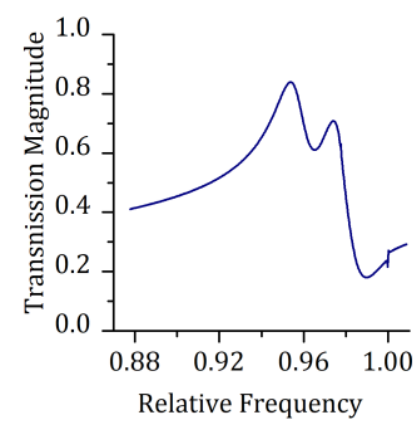

a

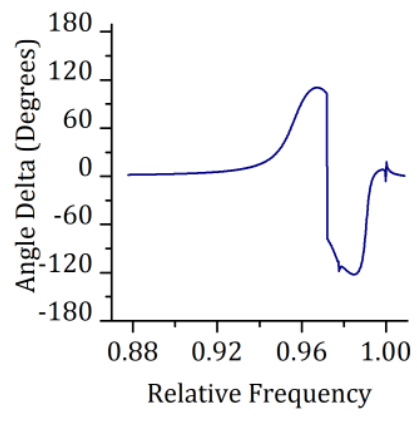

$\mathrm{c}$

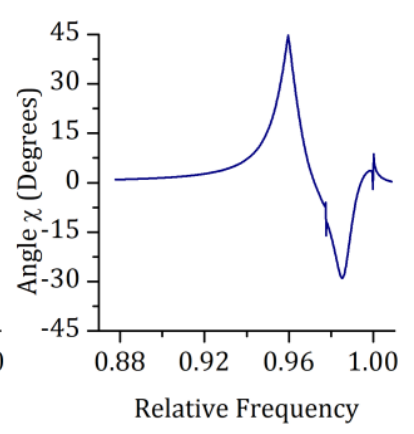

$\mathrm{b}$

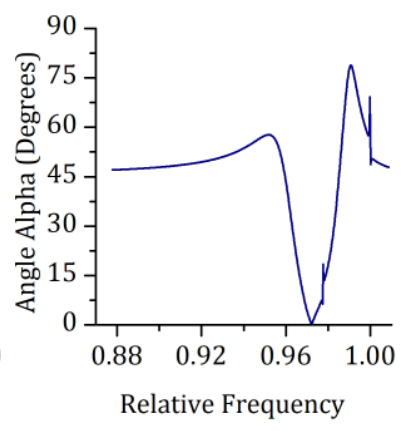

d
Fig. 5 - Transmission response characteristics of plane waves polarized at $\theta=45^{\circ}$ to the $x$-axis for the case of periodicities related to each other as $d_{y}=1.023 d_{x}$ : transmission magnitude (a), the ellipticity angle $\chi(\mathrm{b})$, the auxiliary angle $\delta$ (c), the auxiliary angle $\alpha(\mathrm{d})$

\section{SCREEN EIGENMODES AND CONDITION OF THE MAXIMUM CONVERSION EFFICIENCY}

The described polarization behavior can be explained as a result of coupling of the incident wave with metasurface eigenmodes, which are nontrivial solutions of source free Maxwell equations [21, 22].

For the case, due to the metasurface symmetry with respect to the $x O y$ plane, there are two types of eigenmodes with symmetric $\vec{E}_{p}(x, y, z)=\vec{E}_{p}(x, y,-z)$ and antisymmetric $\vec{E}_{p}(x, y, z)=-\vec{E}_{p}(x, y,-z)$ electric field patterns. Due to the metasurface mirror symmetries with respect to the $x O z$ and $y O z$ planes, those eigenmodes can be presented as two orthogonal sets with electric field distributions oriented along the $x$-axis or $y$-axis, respectively. Moreover, any geometry modification, leading to asymmetry of the supercell along one of the axes, has valuable impact only on eigenmodes with distributions along the corresponding axis, whereas eigenmodes with orthogonal distributions are practically insensitive to such modifications. This happens even if one changes supercell dimensions without any change in supercell filling. In other words, it provides the possibility to control eigenfrequencies and their locations on the complex plane by manipulating with supercell dimensions only. 


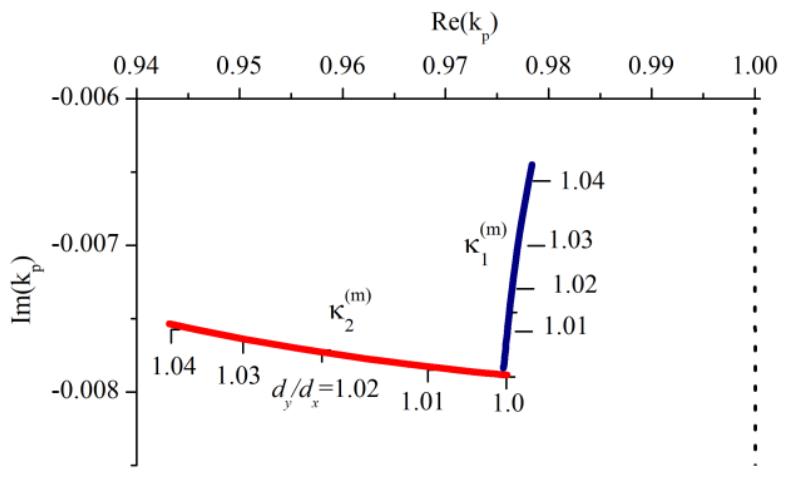

Fig. 6 - The motion of eigenfrequencies on the first sheet of the Riemann surface with changing periodicity $d_{y}$. The dashed line marks the branch cut

Fig. 6 illustrates the motion of eigenfrequencies on the first sheet of the Riemann surface when the periodicity $d_{y}$ changes from $d_{y}=d_{x}$ to $d_{y}=1.04 d_{x}$. The values of $d_{y}$ corresponding to eigenfrequency values are marked on the curves. It is shown trajectories of two eigenfrequencies $\kappa_{1}^{(m)}$ and $\kappa_{2}^{(m)}$ of symmetric eigenmodes with eigenfields oriented along the $x$-axis and $y$-axis, respectively. We do not take into account the eigenfrequencies of the antisymmetric eigenmodes because of their high $Q$-factor, leading to a negligible impact of eigenmodes on the scattering field.

The real part of the eigenfrequency $\kappa_{1}^{(m)}$ shows practically no variation on the sheet. The eigenfrequency $\kappa_{2}^{(m)}$, on the contrary, varies more significantly. Its trajectory starts in the vicinity of $\kappa_{1}^{(m)}$ and moves to a lower frequency domain when $d_{y}$ changes from $d_{y}=d_{x}$ to $d_{y}=1.04 d_{x}$. Therefore, by changing the periodicity $d_{y}$ one can manipulate with the contribution of those eigenmodes to the scattered field to obtain the desired polarization response at certain frequencies.

For the case shown in Fig. 5, the effect of total conversion of a linearly polarized wave into a circularly polarized one in the vicinity of frequency $\kappa=0.95963$ is due to the coupling of the incident wave with orthogonal symmetric eigenmodes. Their eigenfrequencies are $\kappa_{1}^{(m)}=0.9773-i 0.0067$ and $\kappa_{2}^{(m)}=0.9568-i 0.008$.

Those eigenfrequencies are useful to obtain simple approximate formulas for the frequency $\kappa_{C P}$ of linear to circular polarization conversion as well as a level of the conversion efficiency at that frequency.

We can obtain such an approximation, taking into account that transmission magnitudes $T_{x}(\kappa)$ and $T_{y}(\kappa)$ can be approximated by simple formulas [22]

$$
T_{x, y}(\kappa)=\frac{\kappa\left(\kappa^{(m)}-\bar{\kappa}^{(m)}\right)}{\kappa^{2}-k\left(\kappa^{(m)}-\bar{\kappa}^{(m)}\right)-\left|\kappa^{(m)}\right|^{2}}
$$

Thereafter, frequency $\kappa_{C P}$ can be analytically obtained as the solution of equation $\pm i T_{x},(\kappa)=T_{y}(\kappa)$. Its value is

$$
\kappa_{C P}=\sqrt{\frac{\operatorname{Im}\left(\kappa_{1}^{(m)}\right)\left|\kappa_{2}^{(m)}\right|^{2}+\operatorname{Im}\left(\kappa_{2}^{(m)}\right)\left|\kappa_{1}^{(m)}\right|^{2}}{\operatorname{Im}\left(\kappa_{1}^{(m)}\right)+\operatorname{Im}\left(\kappa_{2}^{(m)}\right)}}
$$

Additionally, one can show that the transmission magnitude $\left|T\left(\kappa_{C P}\right)\right|$ reaches the value $\left|T\left(\kappa_{C P}\right)\right|=1 / \sqrt{2}$, when eigenfrequencies $\kappa_{1}^{(m)}$ and $\kappa_{2}^{(m)}$ fulfil the following relation:

$$
\begin{aligned}
& \operatorname{Re}\left(\kappa_{1}^{(m)}\right) \sqrt{1+2\left(\operatorname{Im}\left(\kappa_{1}^{(m)}\right) / \operatorname{Re}\left(\kappa_{1}^{(m)}\right)\right)^{2}}+\operatorname{Im}\left(\kappa_{1}^{(m)}\right)= \\
& =\operatorname{Re}\left(\kappa_{2}^{(m)}\right) \sqrt{1+2\left(\operatorname{Im}\left(\kappa_{2}^{(m)}\right) / \operatorname{Re}\left(\kappa_{2}^{(m)}\right)\right)^{2}}-\operatorname{Im}\left(\kappa_{2}^{(m)}\right) .
\end{aligned}
$$

Therefore, relations (5), (6) are the conditions to get the maximum level of the conversion efficiency possible for ultra-thin single-layer structures. They explain a role of eigenmodes and show a way to improve the conversion efficiency manipulating with eigenfrequencies.

\section{CONCLUSIONS}

The paper describes a design of an ultra-thin quarter wave plate using a fishnet metasurface. The metasurface is arranged as a periodic array of compound supercells with subwavelength circular holes. The proposed design leads to ultra-thin and compact polarization device with simply fabricated geometry elements. The effect of conversion of a linearly polarized wave into a circularly polarized one is explained and the possibility to control the polarization response manipulating with the metasurface geometry parameters is discussed.

\section{REFERENCES}

1. S. Cornbleet, Microwave Optics - The Optics of Microwave Antenna Design, (London: Academic: 1976).

2. H. Chen, A.J. Taylor, N. Yu, Rep. Prog. Phys. 79, 076401 (2016).

3. S.A. Mousavi, E. Plum, J. Shi, N.I. Zheludev, Sci. Rep. 5, 8977 (2015).

4. B. Wang, J. Zhou, T. Koschny, M. Kafesaki, C.M. Soukoulis, J. Opt. A: Pure Appl. Opt. 11 No 11, 114003 (2009).

5. R. Zhao, L. Zhang, J. Zhou, Th. Koschny, C.M. Soukoulis, Phys. Rev. B 83 No 1, 035105 (2011).

6. A.A. Kirilenko, N.G. Kolmakova, A.O. Perov, S.A. Prikolotin, V.N. Derkach, Radioelectron. Commun. Syst. 57 No 12, 521 (2014).

7. X. Xiao, Y. Li, B. Hou, B. Zhou, W. Wen, Opt Lett. 37 No 17, 3594 (2012).

8. A.O. Perov, A.A. Kirilenko, V.N. Derkach, IEEE Antenn. Wirel. Pr. 16, 117 (2017).

9. A.C. Strikwerda, K. Fan, H. Tao, D.V. Pilon, X. Zhang, R.D. Averitt, Opt. Express 17, 136 (2009).

10. Y. Zhang, W. Jin, X. Dong, Z. Zhao, X. Duan, Opt. Express 20 No 10, 10776 (2012).

11. R.M. Roth, N.C. Panoiu, M.M. Adams, J.I. Dadap, R.M. Osgood, Opt. Lett. 32, 3414 (2007).

12. J.Y. Chin, M. Lu, T.J. Cui, Appl. Phys. Lett. 93, 251903 (2008).

13. J. Seo, D. Kim, J. Kang, Q.H. Park, Appl. Phys. Lett. 94, 081102 (2009).

14. A.O. Perov, J. Nano- Electron. Phys. 10 No 6, 06033 (2018).

15. A.O. Perov, J. Opt. 22 No 3, 035102 (2020). 
16. E.H. Khoo, E.P. Li, K.B. Crozier, Opt. Lett. 36, 2498 (2011).

17. A. Roberts, L. Lin, Opt. Lett. 37, 1820 (2012).

18. B. Yang, W.M. Ye, X.D. Yuan, Z.H. Zhu, C. Zeng, Opt. Lett. 38, 679 (2013)

19. T.W. Ebbesen, H.J. Lezec, H.F. Ghaemi, T. Thio, P.A. Wolf, Nature 391, 667 (1998)
20. J.D. Edmunds, E. Hendry, A.P. Hibbins, J.R. Sambles, I.J. Youngs, Opt. Express 19, 13793 (2011).

21. A.O. Perov, Y.K. Sirenko, N.P. Yashina, Prog. Electromagn. Res. 46, 33 (2004)

22. A.A. Kirilenko, A.O. Perov, N.G. Don, Europian Microwave Conference (EuMC 2009), 822 (Rome: IEEE: 2009).

\title{
Сітчаста метаповерхня як ультра тонка чвертьхвильова пластинка
}

\author{
А.О. Перов \\ Інститут радіоббізики та електроніки імені О.Я. Усикова НАН України, \\ вул. акад. Проскури 12, 61085 Харків, Україна
}

\begin{abstract}
В роботі запропоновано конструкцію надтонкої чвертьхвильової пластинки, що базуеться на використанні сітчастої метаповерхні. Метаповерхня влаштована у вигляді періодично розташованих складних суперкомірок, які містять малі в порівнянні з довжиною хвилі кругові отвори. Незважаючи на те, що отвори такої форми не чутливі до поляризації, показано, що можна управляти поляризаційним відгуком, маніпулюючи асиметрією метаповерхневої суперкомірки. Потрібна різниця фраз між компонентами в напрямках осей х та у переданого поля може бути отримана за допомогою вибору розташування отворів у суперкомірці, а також залежить від лінійних розмірів самої суперкомірки. В запропонованій конструкції амплітудою та фразою двох ортогональних компонентів переданого поля можна керувати незалежно, отже, забезпечуючи ефективне та надійне перетворення поляризації. У роботі пояснюеться, що ефект перетворення лінійно поляризованої хвилі в циркулярно поляризовану обумовлено явищем підвищеного пропускання крізь малі отвори та збудженням ортогональних власних коливань метаповерхні. У випадку отворів з малими отворами періодична суперкомірка являе собою складний розсіювач, який формуе відгук та керуе вкладами окремих їі елементів, що призводить до сильної поляризаційної чутливості, яку неможливо спостерігати у випадку круглих резонансних отворів. Аналітично показано, що ефект перетворення поляризації для надтонких метаповерхонь реалізуеться при збудженні двох ортогональних власних коливань з близько розташованими власними частотами. Отримано аналітичні формули для опису поляризаційних ефектів як функції власних частот та обговорено умови для досягнення максимального рівня ефективності перетворення в надтонких одношарових структурах.
\end{abstract}

Ключові слова: Перетворення поляризації, Чвертьхвильова пластинка, Малі отвори, Метаповерхня. 